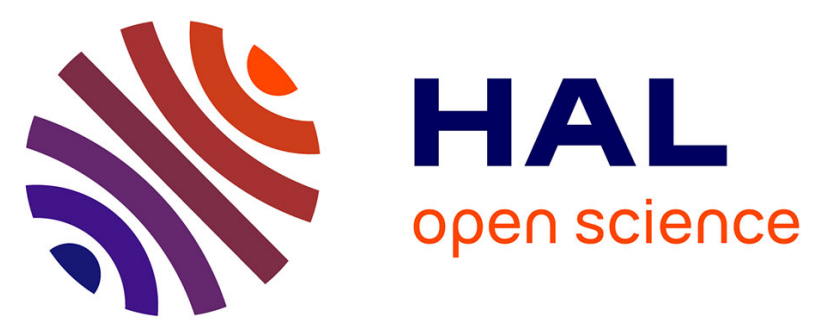

\title{
The kinase inhibitor cyclohexylmethylguanine (NU2058) potentiates the cytotoxicity of cisplatin by mechanisms that are independent of its effect upon CDK2
}

\author{
Luke R.E. Harrison, Christopher J. Ottley, D. Graham Pearson, Roger J. \\ Griffin, Stephen R. Wedge, M. Eileen Dolan, David R. Newell, Michael J. \\ Tilby
}

\section{To cite this version:}

Luke R.E. Harrison, Christopher J. Ottley, D. Graham Pearson, Roger J. Griffin, Stephen R. Wedge, et al.. The kinase inhibitor cyclohexylmethylguanine (NU2058) potentiates the cytotoxicity of cisplatin by mechanisms that are independent of its effect upon CDK2. Biochemical Pharmacology, 2009, 77 (10), pp.1586. 10.1016/j.bcp.2009.02.018 . hal-00493497

\section{HAL Id: hal-00493497 https://hal.science/hal-00493497}

Submitted on 19 Jun 2010

HAL is a multi-disciplinary open access archive for the deposit and dissemination of scientific research documents, whether they are published or not. The documents may come from teaching and research institutions in France or abroad, or from public or private research centers.
L'archive ouverte pluridisciplinaire HAL, est destinée au dépôt et à la diffusion de documents scientifiques de niveau recherche, publiés ou non, émanant des établissements d'enseignement et de recherche français ou étrangers, des laboratoires publics ou privés. 


\section{Accepted Manuscript}

Title: The kinase inhibitor $O^{6}$-cyclohexylmethylguanine (NU2058) potentiates the cytotoxicity of cisplatin by mechanisms that are independent of its effect upon CDK2

Authors: Luke R.E. Harrison, Christopher J. Ottley, D. Graham Pearson, Roger J. Griffin, Stephen R. Wedge, M.

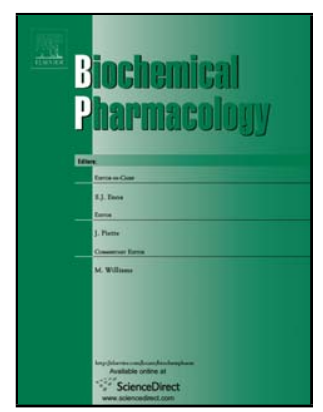
Eileen Dolan, David R. Newell, Michael J. Tilby

PII: S0006-2952(09)00119-1

DOI: doi:10.1016/j.bcp.2009.02.018

Reference: BCP 10098

To appear in: $\quad B C P$

Received date: $\quad$ 1-1-2009

Revised date: $\quad 19-2-2009$

Accepted date: $\quad$ 19-2-2009

Please cite this article as: Harrison LRE, Ottley CJ, Pearson DG, Griffin RJ, Wedge SR, Dolan ME, Newell DR, Tilby MJ, The kinase inhibitor O6cyclohexylmethylguanine (NU2058) potentiates the cytotoxicity of cisplatin by mechanisms that are independent of its effect upon CDK2, Biochemical Pharmacology (2008), doi:10.1016/j.bcp.2009.02.018

This is a PDF file of an unedited manuscript that has been accepted for publication. As a service to our customers we are providing this early version of the manuscript. The manuscript will undergo copyediting, typesetting, and review of the resulting proof before it is published in its final form. Please note that during the production process errors may be discovered which could affect the content, and all legal disclaimers that apply to the journal pertain. 


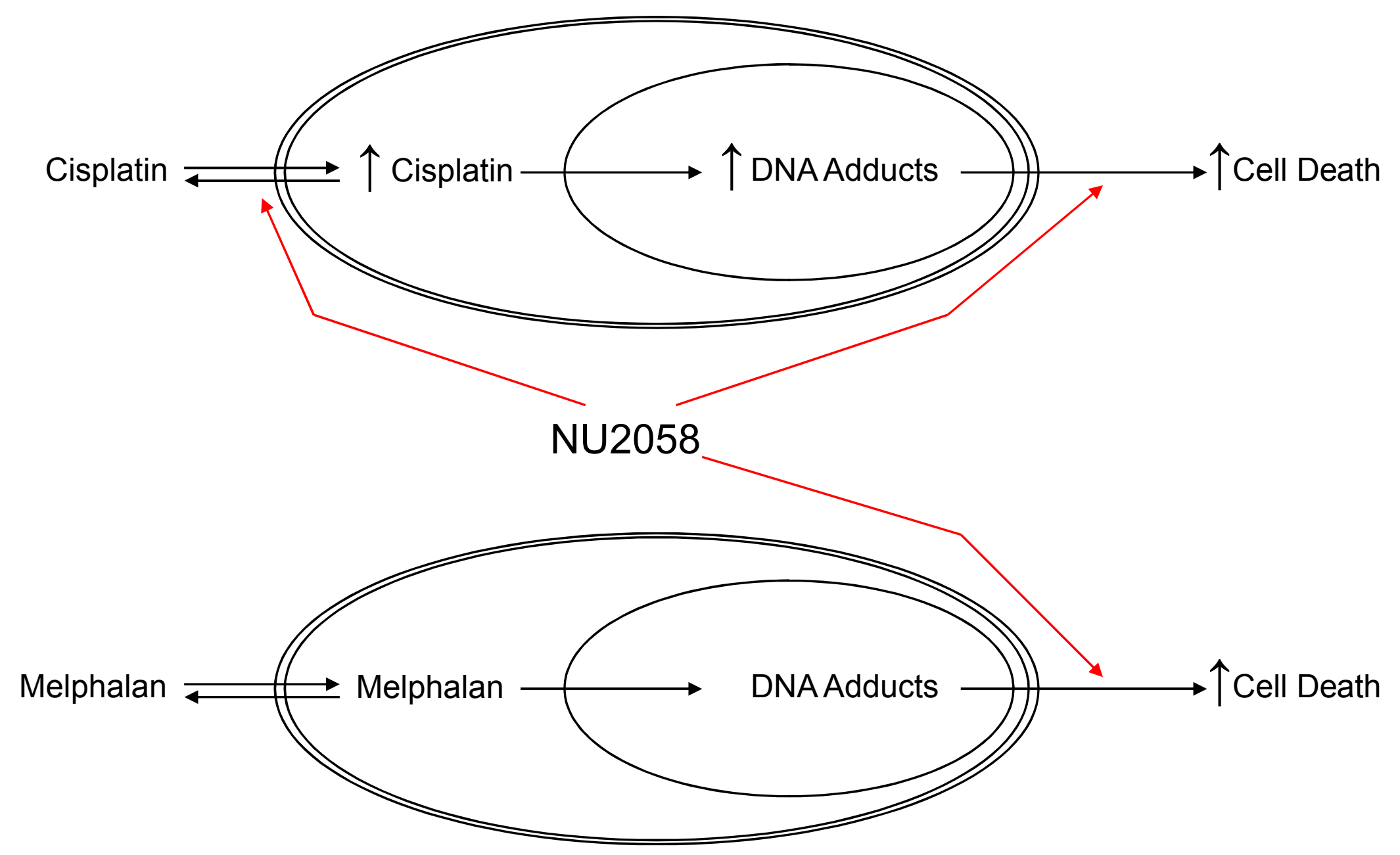


The kinase inhibitor $O^{6}$-cyclohexylmethylguanine (NU2058) potentiates the cytotoxicity of cisplatin by mechanisms that are independent of its effect upon

\section{CDK2}

Luke R.E. Harrison, Christopher J. Ottley, D. Graham Pearson, Roger J. Griffin,

Stephen R. Wedge, M. Eileen Dolan, David R. Newell, Michael J. Tilby

Northern Institute for Cancer Research, Newcastle University, Newcastle upon Tyne, United Kingdom (L.R.E.H., R.J.G., D.R.N., M.J.T.); Department of Geological

Sciences, Durham University, Durham, United Kingdom (C.J.O., D.G.P.); Cancer

Bioscience, AstraZeneca, Alderley Park, Macclesfield, UK (S.R.W.); Department of

Medicine, Committee on Cancer Biology and Cancer Research Center, University of

Chicago, Chicago, Illinois, USA (M.E.D.).

Running title - Protein kinase inhibitors and DNA damaging agents.

Key words - cisplatin, melphalan, potentiation, kinase inhibitor, NU2058

Abbreviations used: CDK, cyclin dependent kinase; DMSO, dimethylsulphoxide;

DMF, Dose Modification Factor; HPLC, high performance liquid chromatography;

ICP-MS, inductively coupled plasma mass spectroscopy; IR, ionising radiation; $\mathrm{Rb}$, retinoblastoma protein. 


\begin{abstract}
$O^{6}$-Cyclohexylmethylguanine (NU2058) was developed as an inhibitor of CDK2 and was previously shown to potentiate cisplatin cytotoxicity in vitro. The aim of this study was to investigate the mechanism of cisplatin potentiation by NU2058.
\end{abstract}

SQ20b, head and neck cancer cells were treated for 2 hours with NU2058 $(100 \mu \mathrm{M})$ and then for a further 2 hours with cisplatin and NU2058. NU2058 increased cisplatin cytotoxicity, by clonogenic assay, with a dose modification factor (DMF) of 3.1.

NU2058 increased total intracellular platinum levels 1.5-fold, and platinum-DNA adduct levels 2-fold. Furthermore, the cisplatin-DNA adducts formed were more toxic in the presence of NU2058. To investigate whether the effects of NU2058 on cisplatin adduct levels and toxicity were dependent on CDK2 activity, additional CDK2 inhibitors were tested. NU6230 (CDK2 IC $5018 \mu \mathrm{M})$ was equipotent to NU2058 $\left(\mathrm{CDK} 2 \mathrm{IC}_{50} 17 \mu \mathrm{M}\right)$ as a CDK2 inhibitor in cell-free and cell-based assays, yet did not potentiate cisplatin cytotoxicity. Furthermore, NU6102 was $>1000$-fold more potent than NU2058 as a CDK2 inhibitor (CDK2 $\left.\mathrm{IC}_{50} 5 \mathrm{nM}\right)$ yet was no more active than NU2058 in potentiating cisplatin.

\footnotetext{
NU2058 also potentiated melphalan (DMF 2.3), and monohydroxymelphalan (1.7), but not temozolomide or ionising radiation. While NU2058 increased melphalan cytotoxicity, it did not increase melphalan-DNA adduct formation.
} 


\section{Introduction}

Platinum compounds such as cisplatin and carboplatin remain amongst the most widely used chemotherapeutic drugs in the treatment many tumours types, including head and neck, testicular, lung, and ovarian carcinomas. For example, the combination of bleomycin, etoposide and cisplatin is considered curative therapy for testicular cancer, with survival rates of over 95\% [1]. Like most cytotoxic anticancer drugs, cisplatin acts via the induction of DNA damage involving a number of types of DNA adducts [2].

Although cisplatin has clinical utility against some tumour types it has little activity against others. Furthermore, initially sensitive tumours can become resistant to platinum complexes. Acquired as well as intrinsic cisplatin resistance can be caused by several mechanisms, including altered drug uptake, increased activity of cellular detoxification systems and DNA repair [3-8]. Modulation of cellular responses to established drugs such as cisplatin have the potential to both improve efficacy and attenuate toxicity.

Protein kinases are involved in a wide range of cellular events including cell growth, DNA repair, replication and cell survival. Many protein kinases are deregulated in the development and progression of cancer, and protein kinase inhibitors are currently being used therapeutically to exploit the molecular pathology of neoplasms. Trastuzumab and imatinib are two clinically successful anti-cancer drugs which act via inhibition of kinase signalling pathways $[9,10]$. Encouraged by the success of imatinib and trastuzumab, the identification of protein kinases that are deregulated in 
cancer and the development of kinase inhibitors is currently a major drug discovery priority.

Cyclin dependent kinases (CDK), and their partner cyclins, are key proteins in the regulation of the cell cycle and are frequently deregulated in cancer cells [11]. The CDKs have been investigated as targets for cancer therapy and the antitumour activity of CDK inhibitors has been demonstrated in preclinical models, both in vitro and in vivo [12]. However, CDK inhibitors have so far shown little or no single agent clinical activity, with the possible exception of flavopiridol for the treatment of chronic lymphocytic leukaemia [13]. These latter data are consistent with preclinical studies, where inhibition of CDKs by flavopiridol was shown to induce cell death [14]. It has also been suggested that CDK inhibitors could be used to increase the efficacy of cytotoxic therapies by modulating cellular responses, possibly by recruiting or holding cells in a drug sensitive phase of the cell cycle [15].

$O^{6}$-Cyclohexylmethylguanine (NU2058, Fig. 1A) is a compound that was identified in a programme to develop potent and selective inhibitors of CDK2. NU2058 showed modest inhibition of $\mathrm{CDK} 2$ with an $\mathrm{IC}_{50}$ (concentration required to give $50 \%$ inhibition of CDK2 in an isolated enzyme assay) value of $17 \mu \mathrm{M}$ [16]. NU2058 has previously been shown to potentiate the cytotoxicity of cisplatin in vitro [17] and it was hypothesised that inhibition of CDK2 was responsible for this effect.

In the present work, we tested the hypothesis that CDK2 inhibition was responsible for the potentiation of cisplatin cytotoxicity by NU2058 through the use of two structurally-related compounds; NU6102 and NU6230 (Fig. 1A). Furthermore, to 
improve our understanding of the mechanism of potentiation of cisplatin by NU2058

we also investigated: 1) whether NU2058 affected cisplatin-DNA interactions and cellular drug uptake; 2) if NU2058 potentiated the cytotoxicity of other DNA damaging agents; 3) whether the effect of NU2058 on potentiation of cisplatin was schedule dependent. 


\section{Methods}

\subsection{Materials}

All materials were purchased from Sigma-Aldrich (UK) unless otherwise stated.

Monohydroxymelphalan was synthesised according to Tilby et al [18].

Temozolomide was provided by the Cancer Research UK Formulation Unit,

Strathclyde University, UK. Cells were irradiated using X-rays $(310 \mathrm{kV}$, dose rate 3

Gy per min.). NU2058, NU6230, NU6102 were synthesised as described previously

$[16,19]$ and stored as $100 \mathrm{mM}$ stock solutions in DMSO at $-20^{\circ} \mathrm{C}$.

\subsection{Cell lines}

The human head and neck cancer cell line, SQ20b, was kindly provided by Dr.

Michael Beckett (Department of Radiation and Cellular Oncology, University of

Chicago, USA) and maintained in DMEM: Ham's F-12 medium, supplemented with $20 \%(\mathrm{v} / \mathrm{v})$ foetal calf serum, and $0.4 \mu \mathrm{g} / \mathrm{ml}$ hydrocortisone, as previously described [20]. Cells were grown in the presence of penicillin (100 units/ml) and streptomycin $(100 \mu \mathrm{g} / \mathrm{ml})$ at $37{ }^{\circ} \mathrm{C}$ and $5 \% \mathrm{CO}_{2}$.

\subsection{Colony formation assay}

Cells were seeded into 6 well plates (350,000 cells/well) and allowed to attach overnight. On the day of the experiment, growth media were replaced with media containing $100 \mu \mathrm{M}$ of either NU2058, NU6102, NU6230 or DMSO (0.1\% (v/v) final concentration) for 2 hours followed by a further 2 hours in the additional presence of cytotoxic drugs, unless otherwise indicated. For the radiation experiments, cells were treated for a total of 4 hours with NU2058, and irradiated after the first 2 hours. After treatment, the cells were washed twice with PBS, trypsinised, and replated into 100 
$\mathrm{mm}$ Petri dishes at various cell densities ( $300-50,000$ cells per plate). After approximately 12 days, media was removed, and cells were fixed with Carnoy's reagent $(75 \%(\mathrm{v} / \mathrm{v})$ methanol, $25 \%(\mathrm{v} / \mathrm{v})$ acetic acid), stained with crystal violet $(0.4 \%$ $(\mathrm{w} / \mathrm{v})$ in water) and colonies were counted using a ColCount ${ }^{\mathrm{TM}}$ image analyser (Oxford Optronix, UK). Percentage survival was calculated relative to the survival of control cells, treated with the compound vehicle alone (DMSO).

\subsection{Western blotting}

Phosphorylation of retinoblastoma protein $(\mathrm{Rb})$ was measured in cells after incubation with each compound or DMSO. Exponentially growing cells were treated in $15 \mathrm{~cm}$ dishes with $100 \mu \mathrm{M}$ of either NU2058, NU6230, NU6102 or vehicle (0.1 \% (v/v) DMSO) for a period of 4 or 24 hours. After treatment, cells were washed twice with ice cold PBS, and lysed with Laemmli buffer [21]. Samples were sonicated and protein concentration quantified using BCA protein assay (Pierce, USA). Equal amounts of protein $(15 \mu \mathrm{g})$ were separated on a 4-20\% (w/v) tris-glycine SDS polyacrylamide gel (Invitrogen, UK) and transferred to a PVDF blotting membrane (BioRad, USA). The membrane was blocked in 5\% (w/v) milk in tris buffered saline containing $0.2 \%(\mathrm{v} / \mathrm{v})$ tween (TBST), and the primary monoclonal phosphospecific $\left(\mathrm{pRb}-\mathrm{T}^{821}\right.$ ) antibody (Biosource, CA, Cat. No. 44-582G) was added at a dilution factor of 1:1000 for two hours, washed with TBST, and incubated with a rabbit secondary antibody (DakoCytomation, Denmark, Cat. No. P0217) in TBST containing 5\% (w/v) milk for a further two hours. The ECL system (Pierce, USA) was used for detection of phospho-Rb. The image was captured with photographic film and developed. For measurement of actin, membranes were incubated as above but with a primary anti- 
actin (Sigma, UK. Cat. No. A4700) and with a rabbit anti-mouse secondary antibody (DakoCytomation, Denmark, Cat. No. P0260).

\subsection{Measurement of total cellular platinum and platinum-DNA adducts}

Actively growing cells were treated with NU2058 $(100 \mu \mathrm{M})$ or DMSO control for 2 hours and then a further 2 hours in the additional presence of cisplatin $(0-50 \mu \mathrm{M})$. After treatment, cells were either washed twice with ice-cold PBS, trypsinised and collected by centrifugation, or washed twice with warm growth medium and further incubated at $37^{\circ} \mathrm{C}$ for periods up to 24 hours. For platinum-DNA adduct analysis, DNA was extracted from cells using the Qiagen DNeasy kit according to the manufacturer's instructions (Qiagen, UK). Isolated DNA was quantified by measuring $\mathrm{OD}_{260}$ using a ND-1000 Spectrophotometer (NanoDrop, USA). Extracted DNA was hydrolysed with 3.5\% nitric acid (v/v) Spectrosol grade (Merck, UK) overnight at $70^{\circ} \mathrm{C}$, prior to analysis by inductively coupled plasma mass spectroscopy (ICP-MS). For measurement of total cellular platinum, cell pellets were sonicated and protein measured as described above. Samples were then incubated with $1 \mathrm{M} \mathrm{NaOH}$ for 1 hour at $60^{\circ} \mathrm{C}$, followed by an overnight acid hydrolysis with $1 \mathrm{M}$ nitric acid at $70^{\circ} \mathrm{C}$. Platinum concentrations in samples were determined by ICP-MS as described previously [22], and compared to a standard curve analysed on the same day to correct for any instrument drift.

\subsection{Measurement of melphalan-DNA adducts}

For measurement of melphalan-DNA adducts, cells were pre-treated with $100 \mu \mathrm{M}$ NU2058 or vehicle $(0.1 \%(\mathrm{v} / \mathrm{v})$ DMSO) for two hours followed by a further two hours in the additional presence of melphalan $(0-50 \mu \mathrm{M})$. After drug treatment, cells were 
washed twice with ice-cold PBS and released using trypsin. Cells were then centrifuged and washed once more with PBS, and pellets were stored at $-20^{\circ} \mathrm{C}$ until required. DNA was extracted using the phenol hydroxyapatite method as described by Tilby et al [18]. DNA concentration was determined by measuring $\mathrm{OD}_{260}$ using a ND1000 Spectrophotometer (NanoDrop, USA). Melphalan-DNA adducts were quantified using a competitive ELISA as described previously [23]. Briefly, several dilutions of DNA from treated cells were mixed with a constant amount of MP5/73 antibody, which was specific for melphalan-guanine adducts on DNA, and incubated in wells coated with a standard amount of melphalan-treated DNA. The amount of antibody that bound to the wells was determined by a fluorogenic enzyme assay. The quantities of adducts per assay well that caused a $50 \%$ reduction of the assay signal were determined by a curve fitting procedure. 


\section{Results}

\subsection{NU2058 did not markedly inhibit CDK2 activity in vitro}

The hypothesis that NU2058-enhanced cisplatin cytotoxicity is due to CDK2 inhibition was tested through a comparative study with the structurally-related compounds NU6230 and NU6102 (Fig. 1A). NU6230 (CDK2 $\left.\mathrm{IC}_{50}=18 \mu \mathrm{M}\right)$ is an equipotent CDK to inhibitor to NU2058 (CDK2 $\left.\mathrm{IC}_{50}=17 \mu \mathrm{M}\right)$, whilst NU6102 $\left(\mathrm{CDK} 2 \mathrm{IC}_{50}=5 \mathrm{nM}\right)$ is $>1000$-fold [19] more potent as an inhibitor of this enzyme. The effects of NU2058, NU6230, and NU6102 on cisplatin cytotoxicity were evaluated by treating SQ20b cells for 2 hours with each compound alone at a concentration of $100 \mu \mathrm{M}$, followed by a further 2 hours with each compound in the presence of cisplatin. All compounds were non-toxic when used alone in the absence of cisplatin, using the schedule described. The previously reported pronounced potentiation of cisplatin cytotoxicity by NU2058 in SQ20b cells [17] was confirmed (Fig. 1B). In these experiments the $\mathrm{LC}_{50}$ values (concentration of cytotoxic drug that reduces plating efficiency by 50\%) were determined. NU2058 enhanced cisplatininduced cell death with a dose modification factor (DMF) of 3.1 fold ( $p<0.001$, twoway ANOVA). DMF is defined as the ratio of the $\mathrm{LC}_{50}$ for cytotoxic drug alone to the $\mathrm{LC}_{50}$ for combined treatment with cytotoxic drug and NU2058 (or NU6102 / NU6230).

NU6102 significantly enhanced the cytotoxicity of cisplatin (Fig. 1B), with a DMF of $2.3(\mathrm{p}<0.05$, two-way ANOVA). In contrast, NU6230 caused no significant enhancement of cisplatin mediated cell death (Fig. 1B, p < 0.05, two-way ANOVA). To evaluate whether the failure of NU6230 to enhance the cytotoxicity of cisplatin was due to inadequate intracellular accumulation of the compound, and hence failure 
to inhibit $\mathrm{CDK} 2$, the effects of the compounds on the phosphorylation of $\mathrm{Rb}$ at threonine 821 were measured, a well characterised CDK2 phosphorylation site [24]. Attempts to re-probe the membranes for total $\mathrm{Rb}$ failed to give reproducible results, and so actin was used as a loading control. Cells incubated with NU6102 for 4 and 24 hours showed a clear reduction in levels of phospho-Rb (Fig. 1C). NU2058 and NU6230 caused a slight decrease in Rb phosphorylation after four hours and a clear decrease after 24 hours. Thus NU6230 was at least as effective as NU2058 at decreasing the phosphorylation of $\mathrm{Rb}$ in a cell-based assay, and at inhibiting CDK2 in a cell-free enzyme assay, but did not potentiate cisplatin cytotoxicity. Conversely, NU6102 was markedly more effective than NU2058 in both cell-free and cell-based CDK2 assays, but was no more effective than NU2058 at potentiating cisplatin cytotoxicity. Together, these data do not support the hypothesis that the potentiation of cisplatin cytotoxicity by NU2058 is due to CDK2 inhibition.

\subsection{NU2058 increased cellular levels of cisplatin and Pt-DNA adducts without}

\section{affecting DNA repair}

To investigate whether the increased cytotoxicity of cisplatin in the presence of NU2058 was due to effects on drug-DNA interaction, cells were harvested immediately after drug treatment, DNA extracted, and the amount of platinum bound to DNA measured using ICP-MS. Platinum-DNA adducts were linearly related to extracellular cisplatin concentration, and NU2058 increased the number of platinumDNA adducts by 2 -fold (Fig. 2A, p $<0.001$ ). The formation and loss of DNA-adducts over time was examined in cells treated with NU2058 or vehicle $(0.1 \%$ (v/v) DMSO) for 2 hours followed by a further 2 hours in combination with $25 \mu \mathrm{M}$ cisplatin. Cells were then washed with, and further incubated in, drug-free medium and harvested at 
the indicated times. As shown in Figure 2B, NU2058 again increased the formation of platinum-DNA adducts, but did not alter their subsequent rate of removal.

To investigate whether the increase in cisplatin-DNA adduct formation induced by NU2058 was due to increased intracellular cisplatin levels, the total concentration of platinum in cells after treatment with cisplatin in the presence or absence of NU2058 was evaluated. Total cellular platinum was also linearly related to extracellular cisplatin concentration, and for any given concentration of cisplatin, NU2058 caused a 1.5 fold increase in the levels of cellular platinum (Fig. $2 \mathrm{C}, \mathrm{p}<0.001$ ). To examine whether the increased cytotoxicity of cisplatin in the presence of NU2058 was due solely to increased cisplatin-DNA adduct formation, the relationship between cisplatin-DNA adduct levels and survival was studied by combining data from Figures $1 \mathrm{~B}$ and $2 \mathrm{~A}$ to evaluate the cytotoxicity as a function of DNA adduct levels. Figure 2D shows that for equal levels of cisplatin-DNA adducts, cell survival was lower in the presence of NU2058.

\subsection{Potentiation of cisplatin cytotoxicity by NU2058 was highly schedule}

\section{dependent}

To determine whether the sequence of drug administration was important for the enhancement of cisplatin cytotoxicity by NU2058, various treatment schedules were studied. Exposure to cisplatin for all schedules was for two hours, and the sequence of cisplatin and NU2058 treatments was as described in the figure legend (Fig. 3). Schedules that involved no overlap of NU2058 and cisplatin exposure produced no significant potentiation of cisplatin cytotoxicity (Fig. 3A and 3D), and the 
enhancement of cisplatin cytotoxicity by NU2058 was therefore dependent on both drugs being present simultaneously (Fig. 3B and C).

\subsection{NU2058 potentiated melphalan and monohydroxymelphalan but not} temozolomide or ionising radiation

The ability of NU2058 to potentiate other DNA damaging agents was investigated. NU2058 potentiated the cytotoxic effects of melphalan (DMF of $2.2(p<0.05$, twoway ANOVA)) and monohydroxymelphalan (DMF of $2.1(\mathrm{p}<0.05$, two-way ANOVA)), but not temozolomide ( $p=0.22$, two-way ANOVA) or ionising radiation $(p=0.99$, two-way ANOVA) (Fig. 4A-D). Since NU2058 increased cisplatin-DNA adduct levels (Fig. 2A), the effect of NU2058 on melphalan-DNA adduct levels was studied using an immunoassay based on an antibody that is specific for melphalanguanine adducts. Although, in contrast to cisplatin, NU2058 did not affect melphalan-DNA adduct levels ( $p>0.05$, two-way ANOVA, Fig. 5A), NU2058 did increase the cytotoxicty of the adducts formed (Fig. 5B). 


\section{Discussion}

The primary aim of this study was to investigate the mechanism by which NU2058 potentiates cisplatin cytotoxicity. NU2058 was developed as an inhibitor of CDK2, and to determine whether its effect on cisplatin cytotoxicity was mediated via CDK2 inhibition, two structurally-related compounds, NU6102 and NU6230, were also studied. NU6230 showed no potentiation of cisplatin (Fig. 1B) despite being similar to NU2058 in its ability to inhibit purified CDK2 (NU2058 CDK2 $\mathrm{IC}_{50}=17 \mu \mathrm{M}$; NU6230 CDK2 $\mathrm{IC}_{50}=18 \mu \mathrm{M}$ ). The lack of potentiation of cisplatin cytotoxicity was not due to poor access of NU6230 to CDK2 in cells, because NU6230 caused similar inhibition of Rb phosphorylation to NU2058, a widely used marker of CDK2 activity (Fig. 1C). In contrast to NU6230 and NU2058, NU6102 was a much more potent inhibitor of purified CDK2 (NU6102 $\mathrm{CDK}_{2} \mathrm{IC}_{50} 5 \mathrm{nM}$ ) and, consistent with the greater potency of the compound, exerted a much greater effect on $\mathrm{Rb}$ phosphorylation in SQ20b cells than did NU2058 (Fig. 1C). However, despite its greater potency as a CDK2 inhibitor, NU6102 was no more effective than NU2058 at potentiating cisplatin cytotoxicity. These data demonstrate that inhibition of CDK2 was not the mechanism by which NU2058 potentiated cisplatin cytotoxicity. The effects reported here are not specific to SQ20b cells because comparable potentiation of cisplatin has been observed in other human cell lines representing other types of cancer (for example LoVo and SW620, data not shown).

Since NU2058 and NU6102 inhibit CDK2 by interaction at the ATP binding site [16, 19], and ATP binding sites are found on multiple proteins, we propose that the potentiation of cisplatin and certain other cytotoxic drugs by NU2058, was due to the interaction with another, as yet unknown ATP-binding protein, possibly a protein 
kinase. The lack of efficacy of NU6230 is presumably due to the large substituent at the C-8 position (Fig. 1A), and NU6230 represents an important negative control compound for further mechanistic studies. Since NU2058 is an analogue of guanine it could, in principle, become converted to a nucleotide and even incorporated into DNA. However, the large substituent at the O6-position is likely to compromise the ability of NU2058 to act as a substrate for hypoxanthine/guanine phosphoribosyl transferase, and subsequently nucleotide kinases and DNA polymerase. Nevertheless, we cannot exclude the possibility that the biological effects of NU2058 are related to its activation via the purine salvage pathway.

NU2058 also potentiated the cytotoxicity of carboplatin, oxaliplatin (data not shown) and the nitrogen mustard, melphalan. However, it did not have any effect on the sensitivity of cells to ionising radiation or temozolomide. NU2058 also potentiated the monofunctional derivative of melphalan, monohydroxymelphalan; however, as expected from previous studies with ML-1 cells [25] monohydroxymelphalan was approximately 20 -fold less toxic than melphalan towards SQ20b cells (Fig. 4F). The cytotoxicity of monohydroxymelphalan, and the associated potentiation by NU2058, could not be attributed to low levels of intact bifunctional melphalan being present because HPLC analysis of the monohydroxymelphalan used showed that any such contamination was $<0.2 \%$ ( $\mathrm{H}$. Thomas, personal communication), a level too low to account for the observed cytotoxicity. Therefore, the potentiation of monohydroxymelphalan by NU2058 demonstrates that the potentiation of melphalan by NU2058 was not solely dependent on the bifunctional properties of the latter molecule. 
The lack of potentiation by NU2058 of both temozolomide (a DNA methylating agent) and ionising radiation (which involves DNA single and double strand breaks) demonstrates that the type of DNA damage is an important determinant of the ability of NU2058 to enhance cytotoxicity. Since cisplatin-DNA adduct levels were based on total platinum bound to DNA, they reflect mainly the levels of intra-strand 1,2 crosslinks as these account for the majority of adducts present on DNA [26]. DNA interstrand cross-links could be particularly important for cytotoxicity but [27], since these only constitute about $1 \%$ of the total adducts [28], the present data cannot rule out an effect of NU2058 on repair of these specific lesions despite the lack of any effects of NU2058 on overall cisplatin adduct removal (Fig. 2B). However, as discussed above, the potentiation observed with monohydroxymelphalan unequivocally demonstrates that the effect of NU2058 does not involve a mechanism specific for DNA crosslinks.

Total cellular platinum content following cisplatin exposure was increased 1.5 fold by NU2058 and this could be responsible, fully or in part, for the increase in platinumDNA adduct formation induced by NU2058 (Fig. 2C). NU2058 could affect cellular platinum levels either by causing an increase in cisplatin influx or a decrease in efflux, effects which in turn could cause an increase in drug-DNA interactions. The transport of cisplatin has recently been shown to be related to the transport of copper $[3,4]$, and three copper transporters have been identified which can transport cisplatin; Ctr1, the copper influx carrier protein which passively transports copper across the cell membrane, and ATP7A and ATP7B, two ATP-dependent copper efflux transporters. However, when cell survival was related to level of platinumDNA adducts it was shown that for equivalent adduct levels, cells treated with 
NU2058 showed an approximately 2-fold increase in cytotoxicity in relation to cells treated with cisplatin alone. This latter result suggests that there are two mechanisms involved in the potentiation of cisplatin cytotoxicity by NU2058, 1) that NU2058 affects the transport of cisplatin, resulting in increased DNA adduct formation, and 2) that NU2058 alters the cellular response to the drug-DNA adducts, such that adducts are more toxic.

In contrast to the effect on cisplatin-DNA adducts, NU2058 had no effect on melphalan-DNA adduct levels (Fig. 5), and potentiation was therefore solely due to the increased cytotoxicity of the adducts that were formed. We hypothesise that the mechanism of potentiation of melphalan is the same as the second mechanism proposed above for the potentiation of cisplatin; namely, that NU2058 alters the cellular response to DNA adducts. To investigate whether the altered cellular response induced by NU2508 was related to effects on DNA repair processes, cisplatin-DNA adduct formation and loss were studied. NU2058 did not alter the rate of DNA adduct loss after removal of cisplatin. Furthermore, consistent with the lack of involvement of DNA repair in the effects of NU2058, it is particularly noteworthy that for potentiation of cisplatin by NU2058 it was necessary for both drugs be present simultaneously (Fig. 3), exposure to NU2058 directly after cisplatin, when repair would be expected to be active, having no effect. Further experiments are required to verify this hypothesis.

As shown here, the potentiation of cisplatin was independent of CDK2 inhibition, and hence it seems likely that potentiation by NU2058 was due to effects involving other protein kinases or ATP binding proteins. Although part of the cisplatin potentiation observed was due to an effect on cisplatin transport, the major effect appears to be an 
alteration to the way that cells respond to DNA damage, a response that is common to cisplatin and melphalan. The lack of an effect on temozolomide and IR cytotoxicity could reflect the different cellular response mechanisms to DNA damage caused by these latter two treatments, and since the available data are not consistent with an effect on DNA damage repair, it seems likely that NU2058 is affecting early cellular responses to DNA damage. Phosphorylation events on chromatin have been shown to occur rapidly after cisplatin treatment [29], and could have a role to play in the cellular response to cisplatin. An alternative explanation is that NU2058 is altering the nature or distribution of the DNA damage across the genome, although not necessarily the overall levels. Ongoing in vitro and in vivo experiments are aimed at identifying kinases that could be the targets by which NU2058 and related compounds potentiate the toxicity of cytotoxic drugs, and the therapeutic potential of cisplatinNU2058 combinations.

\section{Acknowledgement}

The authors would like to acknowledge AstraZeneca, the Medical Research Council, and Cancer Research UK for funding this project. 
Figure 1
A) Structures of NU2058, NU6102, and NU6230 and CDK2 IC 50 B) Effect of
NU2058, NU6102 and NU6230 on the cytotoxicity of cisplatin. SQ20b cells were pretreated with each compound alone $(100 \mu \mathrm{M})$ or vehicle $(0.1 \%(\mathrm{v} / \mathrm{v}) \mathrm{DMSO})$ for 2 hours and for a further 2 hours in combination with cisplatin. After treatment cells were assessed for their colony forming ability after 12 days. Points are the mean, and bars are the standard deviation of three separate experiments. C) Effect of compounds on phosphorylation of retinoblastoma protein. Cells were treated with each compound $(100 \mu \mathrm{M})$ for four or 24 hours before analysis by Western blotting for $\mathrm{T}^{821}$-phospho- $\mathrm{Rb}$. Results from three independent experiments are presented.

Figure 2

The effect of NU2058 on DNA-cisplatin adduct levels and cisplatin uptake. A) Cisplatin-DNA adduct levels after treatment of SQ20b cells with $100 \mu \mathrm{M}$ NU2058 or vehicle $(0.1 \%(\mathrm{v} / \mathrm{v}) \mathrm{DMSO})$ for 2 hours followed by a further 2 hours in the presence of cisplatin. Total platinum-DNA adduct levels were measured using ICP-MS. B) Cisplatin-DNA adduct formation and loss over time. Cells were treated with $100 \mu \mathrm{M}$ NU2058 or vehicle $(0.1 \%(\mathrm{v} / \mathrm{v})$ DMSO $)$ between -4 to 0 hours, with cisplatin $(25 \mu \mathrm{M})$ present between -2 and 0 hours. Cells were then incubated in drug free media for up to 24 hours. C) Cellular cisplatin uptake. Cells were treated as described in A), pellets were sonicated and total cellular platinum determined as described in methods. D) Survival of cells in relation to DNA-cisplatin adduct levels. Values were generated using data from Figures 1B) and 2A). 
In Figures $2 \mathrm{~A}-\mathrm{C}$ points are the mean of 3 independent experiments, and bars the standard deviation. In Figures 2A and 2C the lines were fitted by linear regression analysis.

Figure 3

Effect of NU2058 treatment schedules on cisplatin cytotoxicity. SQ20b cells were treated with $100 \mu \mathrm{M}$ NU2058, or vehicle alone (0.1\% (v/v) DMSO). Treatment with cisplatin was for two hours, and NU2058 for 4 hours, and the schedules were as follows; A) NU2058 for four hours prior to cisplatin; B) Two hour pre-treatment with NU2058 followed by two hour co-incubation with cisplatin (the schedule in Figures 1 and 2); C) A two hour co-incubation followed by a two hour post-cisplatin incubation with NU2058 alone; D) A four hour incubation with NU2058 after cisplatin. Cytotoxicity was measured by using a colony formation assay. Each data point represents the mean and bars represent the standard deviation of three separate experiments. Solid bars represent NU2058 $(100 \mu \mathrm{M})$ or vehicle $(0.1 \%$ (v/v) DMSO), checked bars indicate cisplatin.

Figure 4

Effect of NU2058 on the cytotoxicity of various DNA damaging agents. SQ20b cells were treated with $100 \mu \mathrm{M}$ NU2058 or vehicle $(0.1 \%$ (v/v) DMSO) for 2 hours and for a further 2 hours in combination with either A) melphalan; B)

monohydroxymelphalan; C) ionising radiation; D) temozolomide. Cells were assessed as colony forming ability 12 days after treatment. Each data point represents the mean and bars represent the standard deviation of three separate experiments. 
Figure 5

The effect of NU2058 on melphalan-DNA adduct formation A) Cells were treated with $100 \mu \mathrm{M}$ NU2058 for 2 hours followed by a further 2 hours in combination with melphalan. Melphalan-DNA adduct levels were measured by immunoassay as described in the methods. B) Survival of cells in relation to DNA-melphalan adduct levels assessed by combining data from figure 5A and figure 4A. 
1

2

Luke Harrison. Figure 1

A

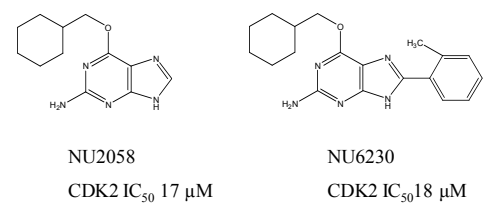

B

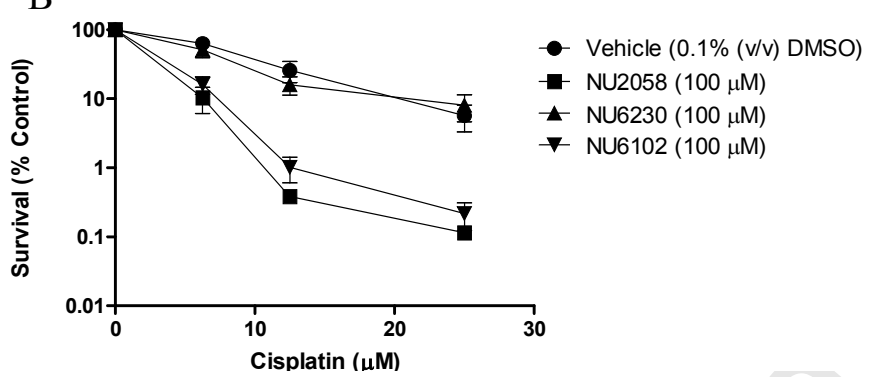

C
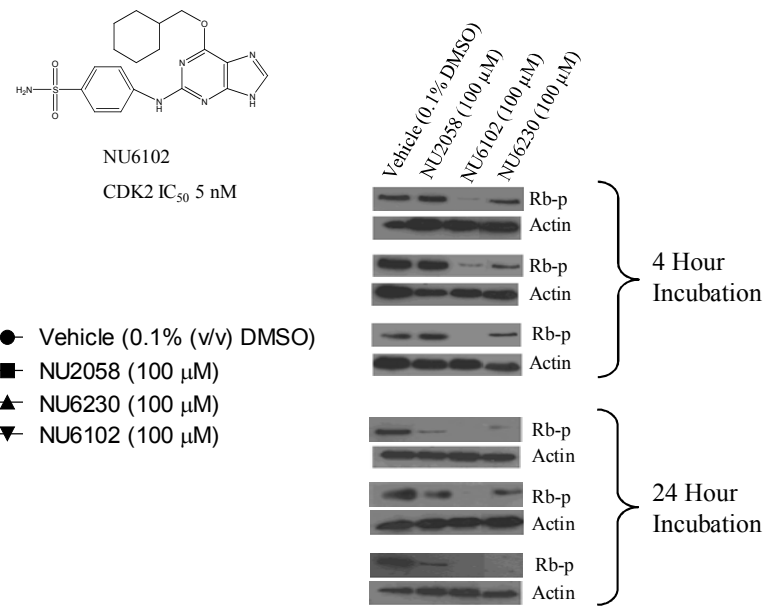
Luke Harrison. Figure 2
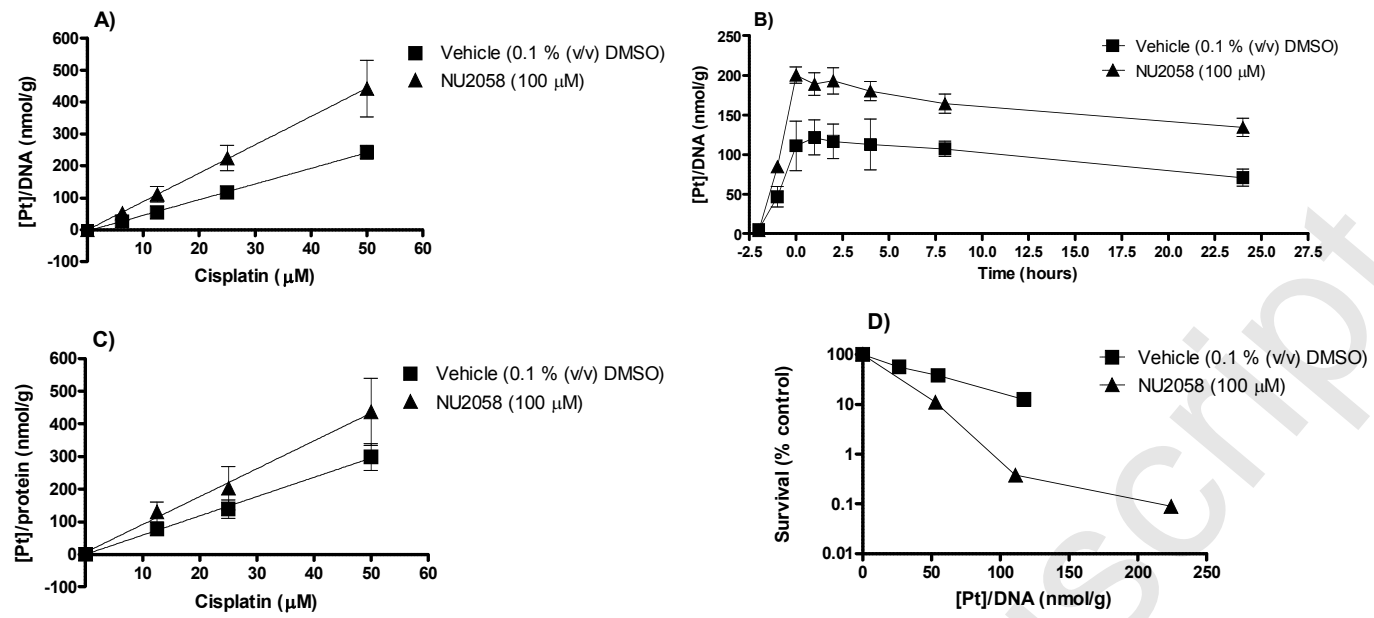
Luke Harrison. Figure 3
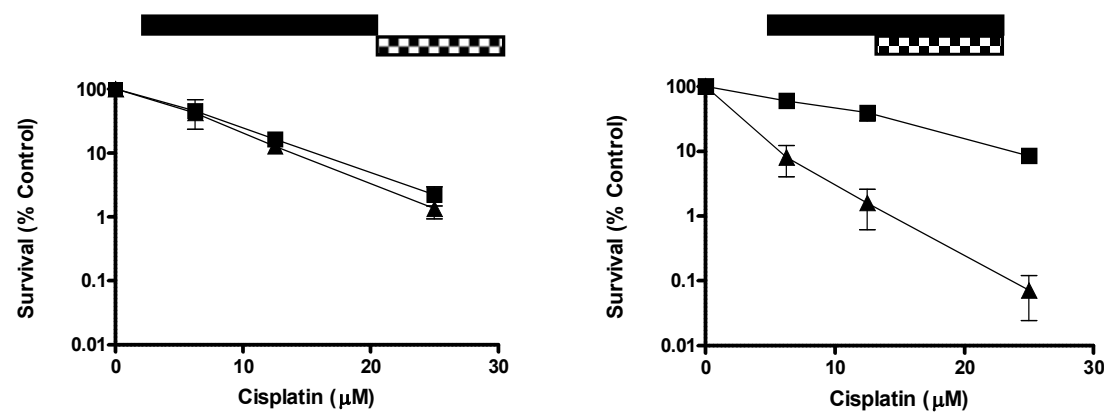

C)
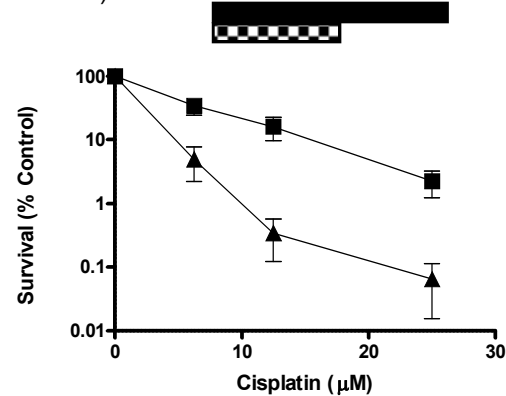

Key: NU2058
D)
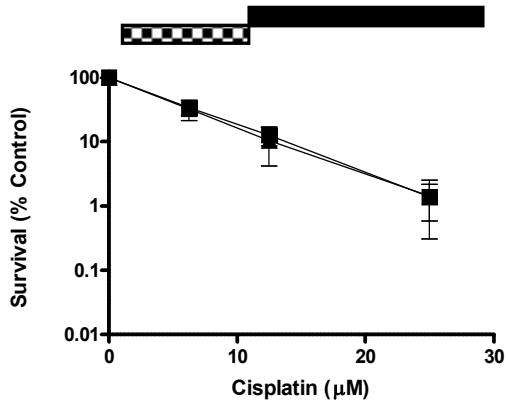

$\rightarrow-$ Vehicle $(0.1 \%(\mathrm{v} / \mathrm{v})$ DMSO) 
Luke Harrison. Figure 4
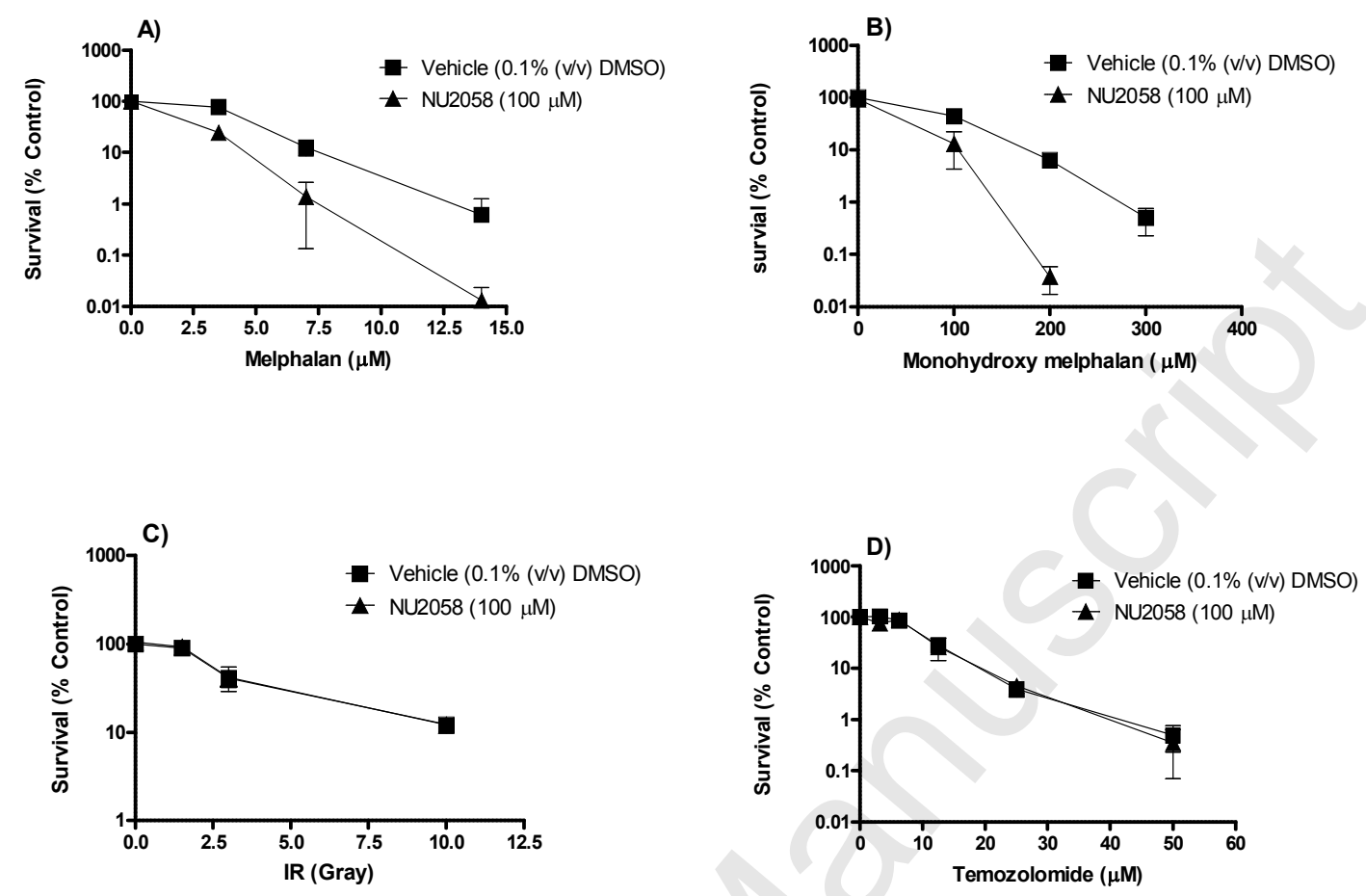
Luke Harrison. Figure 5
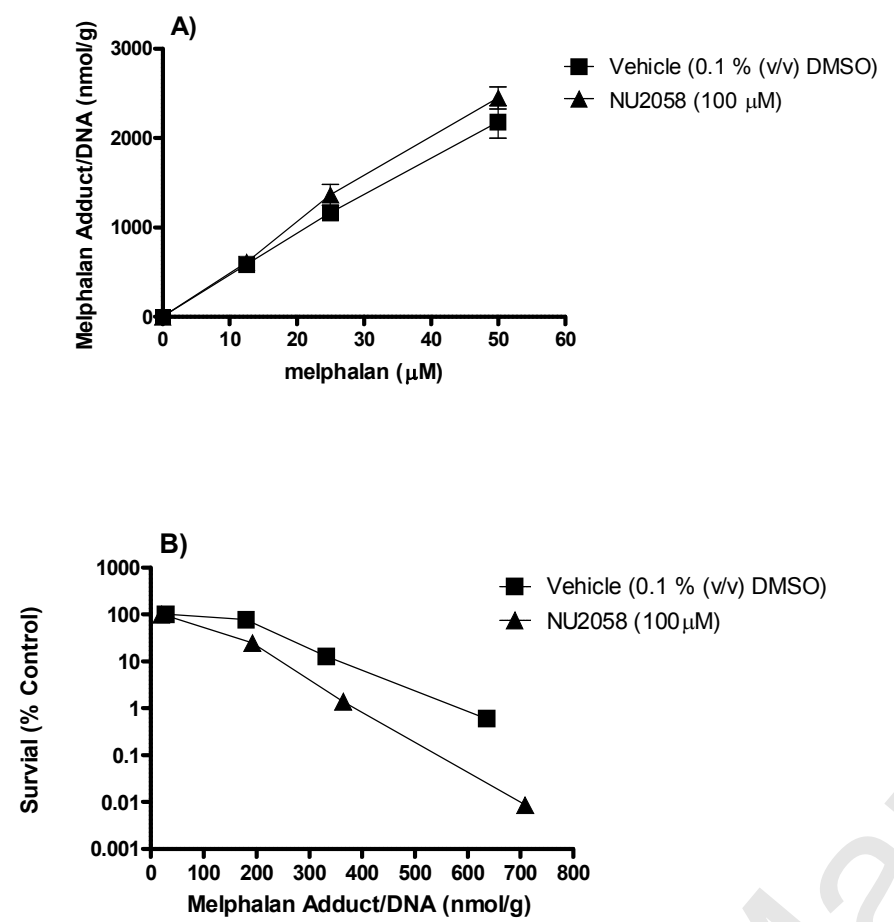


\section{References}

[1] Einhorn LH. Curing metastatic testicular cancer. Proc Natl Acad Sci U S A 2002;99:4592-5 Scopus.

[2] Wang D, Lippard SJ. Cellular processing of platinum anticancer drugs. Nat Rev Drug Discov 2005;4:307-20 Scopus.

[3] Safaei R, Holzer AK, Katano K, Samimi G, Howell SB. The role of copper transporters in the development of resistance to Pt drugs. J Inorg Biochem 2004;98:1607-13 Scopus.

[4] Safaei R, Howell SB. Copper transporters regulate the cellular pharmacology and sensitivity to Pt drugs. Crit Rev Oncol Hematol 2005;53:13-23 Scopus.

[5] Siddik ZH. Cisplatin: mode of cytotoxic action and molecular basis of resistance. Oncogene 2003;22:7265-79 Scopus.

[6] Rabik CA, Dolan ME. Molecular mechanisms of resistance and toxicity associated with platinating agents. Cancer Treat Rev 2007;33:9-23 $\underline{\text { Scopus. }}$.

[7] Boulikas T, Vougiouka M. Cisplatin and platinum drugs at the molecular level. (Review). Oncol Rep 2003;10:1663-82 Scopus.

[8] Fink D, Nebel S, Aebi S, Zheng H, Cenni B, Nehme A, et al. The role of DNA mismatch repair in platinum drug resistance. Cancer Res 1996;56:4881-6 Scopus.

[9] Piccart-Gebhart MJ, Procter M, Leyland-Jones B, Goldhirsch A, Untch M, Smith I, et al. Trastuzumab after adjuvant chemotherapy in HER2-positive breast cancer. N Engl J Med 2005;353:1659-72 Scopus.

[10] Druker BJ, Guilhot F, O'Brien SG, Gathmann I, Kantariian H, Gattermann N, et al. Five-year follow-up of patients receiving imatinib for chronic myeloid leukemia. N Engl J Med 2006;355:2408-17 $\underline{\text { Scopus. }}$.

[11] Shapiro GI. Cyclin-dependent kinase pathways as targets for cancer treatment. J Clin Oncol 2006;24:1770-83 Scopus.

[12] Drees M, Dengler WA, Roth T, Labonte H, Mayo J, Malspeis L, et al. Flavopiridol (L86-8275): selective antitumor activity in vitro and activity in vivo for prostate carcinoma cells. Clin Cancer Res 1997;3:273-9 Scopus.

[13] Byrd JC, Lin TS, Dalton JT, Wu D, Phelps MA, Fischer B, et al. Flavopiridol administered using a pharmacologically derived schedule is associated with marked clinical efficacy in refractory, genetically high-risk chronic lymphocytic leukemia. Blood 2007;109:399-404 Scopus.

[14] Shapiro GI, Koestner DA, Matranga CB, Rollins BJ. Flavopiridol induces cell cycle arrest and p53-independent apoptosis in non-small cell lung cancer cell lines. Clin Cancer Res 1999;5:2925-38 Scopus.

[15] Bible KC, Kaufmann SH. Cytotoxic synergy between flavopiridol (NSC 649890, L86-8275) and various antineoplastic agents: the importance of sequence of administration. Cancer Res 1997;57:3375-80 $\underline{\text { Scopus. }}$.

[16] Arris CE, Boyle FT, Calvert AH, Curtin NJ, Endicott JA, Garman EF, et al. Identification of novel purine and pyrimidine cyclin-dependent kinase inhibitors 
with distinct molecular interactions and tumor cell growth inhibition profiles. J Med Chem 2000;43:2797-804 Scopus.

[17] Fishel ML, Newell DR, Griffin RJ, Davison R, Wang LZ, Curtin NJ, et al. Effect of cell cycle inhibition on Cisplatin-induced cytotoxicity. J Pharmacol Exp Ther 2005;312:206-13 Scopus.

[18] Tilby MJ, Newell DR, Viner C, Selby PJ, Dean CJ. Application of a sensitive immunoassay to the study of DNA adducts formed in peripheral blood mononuclear cells of patients undergoing high-dose melphalan therapy. Eur J Cancer 1993;29A:681-6 Scopus.

[19] Davies TG, Bentley J, Arris CE, Boyle FT, Curtin NJ, Endicott JA, et al. Structure-based design of a potent purine-based cyclin-dependent kinase inhibitor. Nat Struct Biol 2002;9:745-9 Scopus.

[20] Fishel ML, Delaney SM, Friesen LD, Hansen RJ, Zuhowski EG, Moschel RC, et al. Enhancement of platinum-induced cytotoxicity by O6-benzylguanine. Mol Cancer Ther 2003;2:633-40 Scopus.

[21] Laemmli UK. Cleavage of structural proteins during the assembly of the head of bacteriophage T4. Nature 1970;227:680-5 Scopus.

[22] Meczes EL, Azim-Araghi A, Ottley CJ, Pearson DG, Tilby MJ. Specific adducts recognised by a monoclonal antibody against cisplatin-modified DNA. Biochem Pharmacol 2005;70:1717-25 Scopus.

[23] Tilby MJ, Styles JM, Dean CJ. Immunological detection of DNA damage caused by melphalan using monoclonal antibodies. Cancer Res 1987;47:1542-6 Scopus.

[24] Zarkowska T, Mittnacht S. Differential phosphorylation of the retinoblastoma protein by G1/S cyclin-dependent kinases. J Biol Chem 1997;272:12738-46 Scopus.

[25] Gould KA, Nixon C, Tilby MJ. p53 elevation in relation to levels and cytotoxicity of mono- and bifunctional melphalan-DNA adducts. Mol Pharmacol 2004;66:1301-9 Scopus.

[26] Fichtinger-Schepman AM, Lohman PH, Reedijk J. Detection and quantification of adducts formed upon interaction of diamminedichloroplatinum (II) with DNA, by anion-exchange chromatography after enzymatic degradation. Nucleic Acids Res 1982;10:5345-56 Scopus.

[27] Knox RJ, Friedlos F, Lydall DA, Roberts JJ. Mechanism of cytotoxicity of anticancer platinum drugs: evidence that cis-diamminedichloroplatinum(II) and cis-diammine-(1,1-cyclobutanedicarboxylato)platinum(II) differ only in the kinetics of their interaction with DNA. Cancer Res 1986;46:1972-9 Scopus.

[28] Roberts JJ, Friedlos F. Quantitative estimation of cisplatin-induced DNA interstrand cross-links and their repair in mammalian cells: relationship to toxicity. Pharmacol Ther 1987;34:215-46 Scopus.

[29] Wang D, Lippard SJ. Cisplatin-induced post-translational modification of histones H3 and H4. J Biol Chem 2004;279:20622-5 Scopus. 